\title{
Espaçamento reduzido e plantio cruzado associados a diferentes densidades de plantas em soja
}

\section{Narrow row and crossed lines associated with different plant densities of soybean}

\author{
Alvadi Antonio Balbinot Junior ${ }^{1 *}$; Sergio de Oliveira Procópio ${ }^{2}$; \\ Joaquim Mariano Costa ${ }^{3}$; Cristiano Luiz Kosinski ${ }^{4}$; Fernando Panison ${ }^{5}$; \\ Henrique Debiasi ${ }^{1}$; Julio Cezar Franchini ${ }^{1}$
}

\section{Resumo}

O arranjo espacial de plantas de soja afeta a competição intraespecífica por luz, água e nutrientes, podendo alterar a produção de fitomassa, a incidência de pragas, doenças e plantas daninhas, o acamamento de plantas e o rendimento de grãos. O objetivo desse trabalho foi avaliar o desempenho agronômico da soja em função do espaçamento entre as fileiras e plantio cruzado, sob diferentes densidades de plantas. Foram conduzidos dois experimentos em Campo Mourão, PR, utilizando-se o delineamento de blocos completos ao acaso, em esquema fatorial $3 \times 3 \times 2$, com quatro repetições. Os tratamentos foram formados pela combinação de três espaçamentos entre as fileiras $(0,30 ; 0,45$ e $0,60 \mathrm{~m})$, três densidades de plantas $\left(300.000,450.000\right.$ e 600.000 plantas $\left.\mathrm{ha}^{-1}\right)$ e duas disposições das fileiras (plantio cruzado e não cruzado). Para todas as variáveis, não houve interação dos fatores. $\mathrm{O}$ espaçamento de $0,45 \mathrm{~m}$ entre as fileiras proporcionou maior rendimento de grãos em relação aos espaçamentos de 0,30 e 0,60 m. A densidade de 300 mil plantas ha ${ }^{-1}$ proporcionou maior rendimento de grãos de soja em relação às densidades mais altas em semeadura mais tardia. $\mathrm{O}$ plantio cruzado não aumentou o desempenho produtivo na cultura da soja.

Palavras-chave: Glycine max L., espaçamento entre fileiras, arranjo de plantas, componentes de rendimento

\begin{abstract}
The spatial arrangement of soybean plants affects the intraspecific competition for light, water and nutrients, which can change the biomass production, incidence of pests, diseases and weeds, plant lodging, and grain yield. This work aimed to evaluate the agronomic performance under different row spacing, plant densities and crossed rows. Two field experiments were carried out in Campo Mourão, Paraná State, Southern Brazil, using the randomized complete block experimental design, in a $3 \times 3 \times 2$ factorial arrangement, with four replications. The treatments were formed by the combination of three row spacings $(0.30,0.45$, and $0.60 \mathrm{~m})$, three plant densities $\left(300,000 ; 450,000\right.$; and 600,000 plants $\left.^{-1} \mathrm{~h}^{-1}\right)$, and two row design (crossed or parallel rows). For all variables, interaction of the experimental factors
\end{abstract}

1 Engos Agros, Drs., Empresa Brasileira de Pesquisa Agropecuária, EMBRAPA Soja, Londrina, PR. E-mail: alvadi.balbinot@ embrapa.br; henrique.debiasi@embrapa.br; julio.franchini@embrapa.br

2 Eng ${ }^{\circ}$ Agr $^{\circ}$, Dr., Empresa Brasileira de Pesquisa Agropecuária, EMBRAPA Tabuleiros Costeiros, Aracajú, SE. E-mail: sergio. procopio@embrapa.br

3 Eng ${ }^{\circ}$ Agr ${ }^{\circ}$, Coamo, Campo Mourão, PR. E-mail: jmariano@coamo.com.br

4 Discente do Curso de Agronomia, Integrado Faculdade, Coamo, Campo Mourão, PR. E-mail: clkosinski@coamo.com.br

5 Eng $^{\circ}$ Agr $^{\circ}$, Discente do Curso de Doutorado em Produção Vegetal, Universidade do Estado de Santa Catarina, UDESC, Lages, SC. E-mail: fernandopanison@hotmail.com

* Autor para correspondência 
was not significant. The row spacing of $0.45 \mathrm{~m}$ provided the highest grain yield in relation to 0.30 and $0.60 \mathrm{~m}$. The density of 300,000 plants ha $^{-1}$ showed higher yield of soybeans in late sowing. The crossed lines did not increase the productive performance in soybean.

Key words: Glycine max L., row spacing, plant arrangement, yield components

\section{Introdução}

O cultivo da soja sofreu muitas mudanças nas últimas décadas, como a consolidação do sistema plantio direto e o advento das cultivares transgênicas. Especialmente na região Sul do Brasil, houve aumento expressivo da utilização de cultivares de soja que apresentam tipo de crescimento indeterminado, alta precocidade, arquitetura compacta das plantas, folíolos pequenos, menor porte e, sobretudo, alto potencial de rendimento de grãos (PROCÓPIO et al., 2013). No entanto, a densidade de plantas e o espaçamento entre fileiras utilizados se fundamentam em pesquisas e experiências práticas com cultivares que apresentam tipo de crescimento determinado e plantas com alto crescimento vegetativo. Assim, há necessidade de atualização das pesquisas com arranjo de plantas de soja, considerando as cultivares atualmente empregadas.

O arranjo espacial de plantas, determinado pelo espaçamento entre as fileiras e pela densidade de plantas, afeta a competição intraespecífica e, consequentemente, a quantidade de recursos do ambiente - água, luz e nutrientes - disponíveis para cada indivíduo, podendo influenciar o rendimento de grãos (RAMBO et al., 2004; BRUIN; PEDERSEN, 2008; HANNA et al., 2008; COX; CHERNEY; SHIELDS, 2010; WALKER et al., 2010). Além disso, pode afetar a velocidade de fechamento das entrelinhas (HEIFFIG et al., 2006; SILVA et al., 2013), a produção de fitomassa (COX; CHERNEY, 2011), a arquitetura das plantas (PROCÓPIO et al., 2013), a severidade de doenças (LIMA et al., 2012) e o acamamento (BALBINOT JUNIOR, 2011).

Vários trabalhos têm demonstrado a baixa resposta da cultura da soja às variações de densidade de plantas (PIRES; COSTA; THOMAS, 1998; HEIFFIG et al., 2006; PROCÓPIO et al.,
2013). Esses resultados se devem à alta plasticidade fenotípica dessa espécie, definida como a capacidade da planta alterar sua morfologia e componentes de rendimento a fim de adequá-los às condições impostas pelo arranjo espacial dos indivíduos (COOPERATIVE EXTENSION SERVICE AMES, 1994). Desse modo, a soja possui alta habilidade em compensar menores densidades de plantas, principalmente formando maior número de legumes por indivíduo (HEIFFIG et al., 2006; PROCÓPIO et al., 2013). Em relação ao efeito do espaçamento entre as fileiras, há resultados discrepantes na literatura (RAMBO et al., 2003; HEIFFIG et al., 2006), pois essa resposta é dependente das cultivares e do ambiente de cultivo.

Nos últimos anos, alguns agricultores vêm testando uma técnica de semeadura denominada "Plantio Cruzado", na qual se realiza uma operação de semeadura, posicionando metade das sementes, seguida de outra operação similar, no sentido perpendicular à primeira (PROCÓPIO et al., 2013). Alguns relatos indicaram aumento do rendimento de grãos de soja nessa situação (LIMA et al., 2012). No entanto, na literatura há carência de informações sobre os efeitos dessa técnica sobre a cultura, bem como sobre a sua relação com outras práticas de manejo como a densidade e o espaçamento entre linhas.

O objetivo desse trabalho foi avaliar o desempenho agronômico da soja em função do espaçamento entre as fileiras e do plantio cruzado, sob diferentes densidades de plantas.

\section{Material e Métodos}

Foram conduzidos dois experimentos na Fazenda Experimental da Coamo, Campo Mourão, PR, cujas coordenadas geográficas são: $23^{0} 17^{\prime}$ 09,5”Sul, 
$51^{0} 55^{\prime} 17,4$ " Oeste e altitude de $620 \mathrm{~m}$. O solo da área experimental foi classificado como Latossolo Vermelho Distroférrico, muito argiloso, com teores médios de $700 \mathrm{~g} \mathrm{~kg}^{-1} \mathrm{de}$ argila, $200 \mathrm{~g} \mathrm{~kg}^{-1} \mathrm{de}$ silte e $100 \mathrm{~g} \mathrm{~kg}^{-1} \mathrm{de}$ areia. O primeiro experimento foi implantado no dia 04/11, em sucessão ao milho safrinha, e o segundo no dia 18/11, em sucessão à aveia-preta destinada à cobertura do solo. Em ambos os experimentos, a cobertura vegetal foi dessecada 20 dias antes da semeadura da soja, utilizando-se o herbicida glyphosate (1.080 ge.a. ha-1).

O delineamento experimental foi de blocos completos ao acaso, em esquema fatorial $3 \times 3 \times 2$, com quatro repetições. O primeiro fator foi três espaçamentos entre as fileiras $(0,30,0,45$, e $0,60 \mathrm{~m})$, o segundo três densidades de plantas (300.000, 450.000 e 600.000 plantas ha-1) e o terceiro duas disposições das fileiras (plantio cruzado e não cruzado). No primeiro experimento, foi realizado o raleio manual das plantas, em V1, a fim de estabelecer as densidades almejadas. No segundo experimento, a quantidade de sementes na semeadura mecanizada foi ajustada para obter as densidades pretendidas, sem realização de raleio. Nos dois ensaios, a quantidade de plantas na colheita foi similar à pretendida (de 90 a $110 \%$ da densidade planejada). Nos espaçamentos de 0,30 e $0,60 \mathrm{~m}$ entre as fileiras, as parcelas apresentaram área total de 27,0 $\mathrm{m}^{2}(3,0 \times 9,0 \mathrm{~m})$ e área útil de 12,6 $\mathrm{m}^{2}(1,8 \times 7,0 \mathrm{~m})$. No espaçamento de $0,45 \mathrm{~m}$ entre as fileiras, as parcelas apresentaram 20,2 $\mathrm{m}^{2}(2,2 \times 9,0$ $\mathrm{m})$ e área útil de $9,4 \mathrm{~m}^{2}(1,3 \times$ 7,0 m). Nos espaços entre as parcelas foi cultivada soja, a fim de reduzir o efeito de bordadura.

Foi utilizada a cultivar de soja BMX Potência RR nos dois experimentos, que possuitipo de crescimento indeterminado e grupo de maturidade relativa 6.7. A semeadura foi realizada a uma velocidade média de $5 \mathrm{~km} \mathrm{~h}^{-1}$, por meio de semeadora-adubadora equipada com facão para disposição do adubo e disco duplo defasado para a semente. As sementes foram tratadas com piraclostrobina, tiofanato metílico e fipronil, nas doses de 5, 45 e 50 g 100 $\mathrm{kg}^{-1}$ de sementes, respectivamente. Posteriormente, foi aplicado cobalto, molibdênio e inoculante nas sementes. A adubação de base foi realizada no sulco e constou da aplicação de $250 \mathrm{~kg} \mathrm{ha}^{-1}$ do adubo formulado 00-20-20 (N-P $\left.\mathrm{O}_{5}-\mathrm{K}_{2} \mathrm{O}\right)$. O controle de pragas, doenças e plantas daninhas foi efetuado conforme as indicações técnicas para a cultura. Os dados de precipitação pluvial e temperatura do ar durante o período de execução dos experimentos estão apresentados na Figura 1.

Figura 1. Precipitação pluvial e temperaturas mínimas e máximas do ar no período de execução dos experimentos.

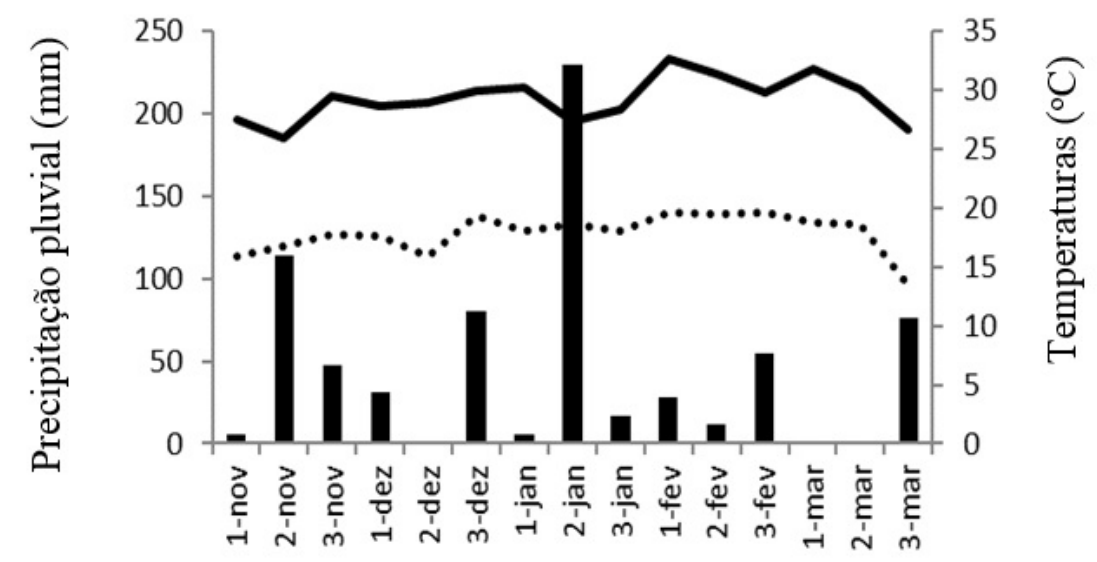

Decêndio - mês

Fonte: Elaboração dos autores. 
$\mathrm{Na}$ colheita, foram realizadas as seguintes avaliações, amostrando-se 15 plantas parcela-1: altura de plantas; altura de inserção do primeiro legume; número de nós no caule; número de ramos planta $^{-1}$; número de legumes no caule planta $^{-1}$; número de legumes nos ramos planta ${ }^{-1}$; porcentagem dos legumes provenientes dos ramos; número de grãos legume ${ }^{-1}$ proveniente do caule; número de grãos legume ${ }^{-1}$ proveniente dos ramos; massa de mil grãos provenientes do caule; massa de mil grãos provenientes dos ramos; porcentagem da massa de grãos provenientes dos ramos; e índice de colheita aparente (relação entre a massa de grãos e o somatório da massa de grãos, caules e legumes sem grãos).

Para avaliação do grau de acamamento das plantas, avaliado no momento da colheita, foi utilizada uma escala de notas variando de 1 a 5 , conforme descrição a seguir: 1 - nenhuma planta da área útil acamada; 2 - 25\% das plantas da área útil acamadas; 3 - 50\% das plantas da área útil acamadas $4-75 \%$ das plantas da área útil acamadas; 5 - 100\% das plantas da área útil acamadas. O rendimento de grãos foi estimado pela colheita das plantas contidas na área útil das parcelas, as quais foram trilhadas e os grãos limpos e pesados, sendo o rendimento corrigido para $13 \%$ de umidade.

Os dados foram submetidos ao teste Bartlett, para verificação da homogeneidade de variâncias. Uma vez que as variâncias foram homogêneas, procederam-se às análises de variância, sem necessidade de transformação dos dados, à exceção da variável número de legumes nos ramos planta ${ }^{-1}$. Quando constatado efeito de tratamentos, as médias foram comparadas pelo teste Tukey $p \leq 0,05$. Também foi realizada análise de correlação linear de Pearson entre o rendimento de grãos e as demais variáveis avaliadas. Para realização da análise estatística, foram utilizados os programas $\mathrm{R}$ ( $\mathrm{R}$ DEVELOPMENT CORE TEAM, 2009) e Sisvar (FERREIRA, 2008).

\section{Resultados e Discussão}

Não houve efeito das interações para todas as variáveis avaliadas. Nos dois experimentos, o maior rendimento de grãos foi observado no espaçamento de 0,45 m, comparativamente aos espaçamentos de 0,30 e $0,60 \mathrm{~m}$ (Tabelas 1 e 2). É provável que no espaçamento de $0,60 \mathrm{~m}$ o rendimento tenha sido limitado em razão do menor aproveitamento da radiação solar, principalmente no início do ciclo de desenvolvimento. Por outro lado, o espaçamento reduzido de $0,30 \mathrm{~m}$ provavelmente aumentou o sombreamento das folhas próximas do solo pelas folhas da parte superior do dossel, além de reduzir a penetração de agroquímicos no dossel. Na literatura, há dados que comprovam o aumento do rendimento de grãos de soja com a adoção de espaçamento reduzido $(0,20$ a $0,30 \mathrm{~m})$, principalmente em decorrência do incremento do índice de área foliar (COX; CHERNEY, 2011), da formação de maior número de flores por área (VENTIMIGLIA et al., 1999) e do aumento do número de legumes por área (RAMBO et al., 2003).

No primeiro experimento, o número de ramos planta $^{-1}$ e a porcentagem de legumes provenientes dos ramos foram inferiores no espaçamento de 0,30 $\mathrm{m}$, comparativamente a $0,60 \mathrm{~m}$ (Tabela 1). Isso demonstra que o maior espaçamento entre as fileiras propiciou melhores condições para a ramificação das plantas; ou seja, a maior disponibilidade de luz nas entrelinhas foi importante para estimular a emissão de ramos, embora houvesse maior concentração de plantas nas linhas. Nessa situação, é esperado que a qualidade da luz nas entrelinhas também seja superior, estimulando a emissão de ramos no sentido perpendicular às fileiras (LUCA; HUNGRIA, 2014). 
Tabela 1. Variáveis agronômicas da cultura da soja, cultivar BMX Potência RR, em diferentes espaçamentos entre fileiras (médias de três densidades de plantas e de duas disposições das fileiras). Primeira época de semeadura (04/11).

\begin{tabular}{|c|c|c|c|c|}
\hline \multirow[t]{2}{*}{ Variáveis agronômicas } & \multicolumn{3}{|c|}{ Espaçamentos entre fileiras (m) } & \multirow[t]{2}{*}{$\mathrm{CV}(\%)$} \\
\hline & 0,30 & 0,45 & 0,60 & \\
\hline Rendimento de grãos $\left(\mathrm{kg} \mathrm{ha}^{-1}\right)$ & $2.993 b^{1}$ & $3.509 \mathrm{a}$ & $2.915 \mathrm{~b}$ & 8,7 \\
\hline Altura de plantas (m) & $1,00 \mathrm{a}$ & $1,02 \mathrm{a}$ & $1,03 \mathrm{a}$ & 5,7 \\
\hline Altura de inserção do primeiro legume (m) & $0,23 \mathrm{a}$ & $0,21 \mathrm{a}$ & $0,23 \mathrm{a}$ & 16,7 \\
\hline Número de nós no caule & $10,3 \mathrm{a}$ & $11,2 \mathrm{a}$ & $10,9 \mathrm{a}$ & 11,8 \\
\hline Número de ramos planta ${ }^{-1}$ & $1,50 \mathrm{~b}$ & $1,80 \mathrm{ab}$ & $2,00 \mathrm{a}$ & 25,7 \\
\hline Número de legumes no caule planta ${ }^{-1}$ & $23,2 \mathrm{a}$ & $25,9 \mathrm{a}$ & $23,3 \mathrm{a}$ & 19,3 \\
\hline Número de legumes nos ramos planta-12 & $8,5 \mathrm{a}$ & $10,2 \mathrm{a}$ & $11,3 \mathrm{a}$ & 21,2 \\
\hline Porcentagem dos legumes provenientes dos ramos & $25,1 \mathrm{~b}$ & $27,2 \mathrm{ab}$ & $29,8 \mathrm{a}$ & 20,6 \\
\hline Número de grãos legume ${ }^{-1}$ do caule & $2,18 \mathrm{a}$ & $2,14 \mathrm{a}$ & $2,13 \mathrm{a}$ & 10,2 \\
\hline Número de grãos legume ${ }^{-1} \mathrm{dos}$ ramos & $2,18 \mathrm{a}$ & $2,24 \mathrm{a}$ & $2,22 \mathrm{a}$ & 11,0 \\
\hline Massa de mil grãos do caule $(\mathrm{g})$ & $123 \mathrm{a}$ & $124 \mathrm{a}$ & $131 \mathrm{a}$ & 13,0 \\
\hline Massa de mil grãos dos ramos (g) & $123 \mathrm{a}$ & $115 \mathrm{a}$ & $117 \mathrm{a}$ & 15,0 \\
\hline Porcentagem da massa de grãos provenientes dos ramos & $25,0 \mathrm{a}$ & $26,4 \mathrm{a}$ & $28,6 \mathrm{a}$ & 21,4 \\
\hline Índice de colheita aparente & $0,41 \mathrm{a}$ & $0,40 \mathrm{a}$ & $0,41 \mathrm{a}$ & 9,7 \\
\hline Nota de acamamento & 1 & 1 & 1 & - \\
\hline
\end{tabular}

${ }^{1}$ Médias seguidas pelas mesmas letras não diferem entre si pelo teste de Tukey a $5 \%$ de probabilidade.

${ }^{2}$ Dados transformados em $\sqrt{ }(x+1)$

Fonte: Elaboração dos autores.

No segundo experimento, em que houve semeadura mais tardia, as variáveis relacionadas à ramificação não foram afetadas pelos espaçamentos (Tabela 2). Nessa condição, houve maior crescimento vegetativo das plantas, em função da maior temperatura (Figura 1) e comprimento do dia no início do ciclo de desenvolvimento, propiciando rápido fechamento das entrelinhas, mesmo nos espaçamentos mais amplos. O maior crescimento das plantas no segundo experimento, semeado em 18/11 (Tabela 2), em relação ao primeiro, semeadura em 04/11 (Tabela 1), é retratado pela maior altura de plantas, maior número de nós no caule e maior acamamento das plantas. Dessa forma, em semeadura mais tardia, os espaçamentos não afetaram a ramificação. As demais variáveis avaliadas não foram influenciadas pelos espaçamentos entre as fileiras (Tabelas 1 e 2).

As variáveis mais correlacionadas com o rendimento de grãos foram o número de legumes no caule principal planta $^{-1}(\mathrm{r}=0,35, \mathrm{p}<0,05)$ e o número de legumes nos ramos planta ${ }^{-1}(\mathrm{r}=0,24, \mathrm{p}<0,05)$. Isso demonstra que as variações de rendimento de grãos em razão do manejo adotado são decorrentes, fundamentalmente, do número de legumes por planta e, consequentemente, por área, sendo as demais características avaliadas pouco afetadas pelo arranjo espacial das plantas. Resultado semelhante foi obtido por Rambo et al. (2004); Boroomandan et al. (2009) e Luca e Hungia (2014).

No primeiro experimento, não houve efeito da densidade de plantas sobre o rendimento de grãos (Tabela 3), demonstrando a grande plasticidade fenotípica da soja (RAMBO et al., 2004; HEIFFIG et al., 2006; COX; CHERNEY, 2011; BOARD; KAHLON, 2013; LUCA; HUNGRIA, 2014). Todavia, no segundo experimento, a menor densidade de plantas conferiu maior rendimento de grãos (Tabela 4), demonstrando que, em semeadura mais tardia, o uso de altas densidades de plantas acentua demasiadamente a competição intraespecífica, tornando a redução da produção por planta mais expressiva do que o aumento no número de plantas por área. De acordo com Board e Kahlon (2013) quanto mais favoráveis são as condições de ambiente à soja, menores são as densidades ótimas para expressão de altas produtividades de grãos, compensando a menor quantidade de plantas pelo maior crescimento e produção por planta. 
Tabela 2. Variáveis agronômicas da cultura da soja, cultivar BMX Potência RR, em diferentes espaçamentos entre fileiras (médias de três densidades de plantas e de duas disposições das fileiras). Segunda época de semeadura (18/11).

\begin{tabular}{|c|c|c|c|c|}
\hline \multirow{2}{*}{ Variáveis agronômicas } & \multicolumn{3}{|c|}{ Espaçamentos entre fileiras (m) } & \multirow{2}{*}{$\mathrm{CV}(\%$} \\
\hline & 0,30 & 0,45 & 0,60 & \\
\hline Rendimento de grãos $\left(\mathrm{kg} \mathrm{ha}^{-1}\right)$ & $3.033 \mathrm{~b}^{1}$ & $3.394 \mathrm{a}$ & $2.827 \mathrm{c}$ & 6,5 \\
\hline Altura de plantas (m) & $1,16 \mathrm{a}$ & $1,14 \mathrm{ab}$ & $1,12 \mathrm{~b}$ & 3,8 \\
\hline Altura de inserção do primeiro legume (m) & $0,21 \mathrm{a}$ & $0,21 \mathrm{a}$ & $0,22 \mathrm{a}$ & 12,2 \\
\hline Número de nós no caule & $12,6 \mathrm{a}$ & $12,4 \mathrm{a}$ & $11,8 \mathrm{a}$ & 10,8 \\
\hline Número de ramos planta ${ }^{-1}$ & $2,21 \mathrm{a}$ & $2,45 \mathrm{a}$ & $2,33 \mathrm{a}$ & 20,3 \\
\hline Número de legumes no caule planta ${ }^{-1}$ & $31,1 \mathrm{a}$ & $31,3 \mathrm{a}$ & $29,4 \mathrm{a}$ & 15,5 \\
\hline Número de legumes nos ramos planta ${ }^{-12}$ & $12,8 \mathrm{a}$ & $14,6 \mathrm{a}$ & $12,1 \mathrm{a}$ & 19,8 \\
\hline Porcentagem dos legumes provenientes dos ramos & $27,6 \mathrm{a}$ & $30,0 \mathrm{a}$ & $25,1 \mathrm{a}$ & 30,8 \\
\hline Número de grãos legume ${ }^{-1}$ do caule & $2,14 \mathrm{a}$ & $2,17 \mathrm{a}$ & $2,13 \mathrm{a}$ & 15,1 \\
\hline Número de grãos legume ${ }^{-1}$ dos ramos & $2,11 \mathrm{a}$ & $2,25 \mathrm{a}$ & $2,48 \mathrm{a}$ & 32,2 \\
\hline Massa de mil grãos do caule (g) & 139 a & $142 \mathrm{a}$ & $138 \mathrm{a}$ & 8,4 \\
\hline Massa de mil grãos dos ramos $(\mathrm{g})$ & $143 \mathrm{a}$ & $138 \mathrm{a}$ & $135 \mathrm{a}$ & 18,5 \\
\hline Porcentagem da massa de grãos provenientes dos ramos & $26,5 \mathrm{a}$ & $26,6 \mathrm{a}$ & $28,9 \mathrm{a}$ & 20,2 \\
\hline Índice de colheita aparente & $0,44 \mathrm{a}$ & $0,43 \mathrm{a}$ & $0,43 \mathrm{a}$ & 5,2 \\
\hline Nota de acamamento & 2,3 & 1,8 & 2,3 & - \\
\hline
\end{tabular}

${ }^{1}$ Médias seguidas pelas mesmas letras não diferem entre si pelo teste de Tukey a 5\% de probabilidade.

${ }^{2}$ Dados transformados em $\sqrt{(x+1)}$

Fonte: Elaboração dos autores.

Tabela 3. Variáveis agronômicas da cultura da soja, cultivar BMX Potência RR, em diferentes densidades de plantas (médias de três espaçamentos entre fileiras e de duas disposições das fileiras). Primeira época de semeadura (04/11).

\begin{tabular}{|c|c|c|c|c|}
\hline \multirow[t]{2}{*}{ Variáveis agronômicas } & \multicolumn{3}{|c|}{ Densidades de plantas $\left(\right.$ mil ha-1) $^{-1}$} & \multirow[t]{2}{*}{$\mathrm{CV}(\%)$} \\
\hline & 300 & 450 & 600 & \\
\hline Rendimento de grãos $\left(\mathrm{kg} \mathrm{ha}^{-1}\right)$ & $3.202 \mathrm{a}^{1}$ & $3.115 \mathrm{a}$ & $3.100 \mathrm{a}$ & 8,7 \\
\hline Altura de plantas (m) & $1,03 \mathrm{a}$ & $1,02 \mathrm{a}$ & $0,99 \mathrm{a}$ & 5,7 \\
\hline Altura de inserção do primeiro legume (m) & $0,21 \mathrm{a}$ & $0,23 \mathrm{a}$ & $0,23 \mathrm{a}$ & 16,7 \\
\hline Número de nós no caule & $12,3 \mathrm{a}$ & $10,4 \mathrm{~b}$ & $9,7 \mathrm{~b}$ & 11,8 \\
\hline Número de ramos planta ${ }^{-1}$ & $2,3 \mathrm{a}$ & $1,6 \mathrm{~b}$ & $1,4 \mathrm{~b}$ & 25,7 \\
\hline Número de legumes no caule planta ${ }^{-1}$ & $30,8 \mathrm{a}$ & $23,7 \mathrm{~b}$ & $19,5 \mathrm{c}$ & 19,3 \\
\hline Número de legumes nos ramos planta ${ }^{-12}$ & $14,7 \mathrm{a}$ & $8,4 \mathrm{~b}$ & $7,0 \mathrm{~b}$ & 21,2 \\
\hline Porcentagem dos legumes provenientes dos ramos & $31,4 \mathrm{a}$ & $24,9 \mathrm{~b}$ & $25,8 \mathrm{~b}$ & 20,6 \\
\hline Número de grãos legume ${ }^{1}$ do caule & $2,20 \mathrm{a}$ & $2,14 \mathrm{a}$ & $2,11 \mathrm{a}$ & 10,2 \\
\hline Número de grãos legume ${ }^{-1}$ dos ramos & $2,15 \mathrm{a}$ & $2,24 \mathrm{a}$ & $2,25 \mathrm{a}$ & 11,0 \\
\hline Massa de mil grãos do caule (g) & $126 \mathrm{a}$ & $127 \mathrm{a}$ & $125 \mathrm{a}$ & 13,0 \\
\hline Massa de mil grãos dos ramos (g) & $124 \mathrm{a}$ & $114 \mathrm{a}$ & $117 \mathrm{a}$ & 15,0 \\
\hline Porcentagem da massa de grãos provenientes dos ramos & $30,4 \mathrm{a}$ & $23,7 \mathrm{~b}$ & $25,9 \mathrm{~b}$ & 21,4 \\
\hline Índice de colheita aparente & $0,41 \mathrm{a}$ & $0,40 \mathrm{a}$ & $0,40 \mathrm{a}$ & 9,7 \\
\hline Nota de acamamento & 1 & 1 & 1 & - \\
\hline
\end{tabular}

${ }^{1}$ Médias seguidas pelas mesmas letras não diferem entre si pelo teste de Tukey a $5 \%$ de probabilidade.

${ }^{2}$ Dados transformados em $\sqrt{ }(x+1)$

Fonte: Elaboração dos autores. 
Tabela 4. Variáveis agronômicas da cultura da soja, cultivar BMX Potência RR, em diferentes densidades de plantas (médias de três espaçamentos entre fileiras e de duas disposições das fileiras). Segunda época de semeadura (18/11).

\begin{tabular}{|c|c|c|c|c|}
\hline \multirow[t]{2}{*}{ Variáveis agronômicas } & \multicolumn{3}{|c|}{ Densidades de plantas $\left(\mathrm{mil} \mathrm{ha}^{-1}\right)$} & \multirow[t]{2}{*}{ CV $(\%)$} \\
\hline & 300 & 450 & 600 & \\
\hline Rendimento de grãos $\left(\mathrm{kg} \mathrm{ha}^{-1}\right)$ & $3.190 \mathrm{a}^{1}$ & $3.018 \mathrm{~b}$ & $3.044 \mathrm{~b}$ & 6,5 \\
\hline Altura de plantas (m) & $1,14 \mathrm{a}$ & $1,15 \mathrm{a}$ & $1,14 \mathrm{a}$ & 3,7 \\
\hline Altura de inserção do primeiro legume (m) & $0,21 \mathrm{a}$ & $0,22 \mathrm{a}$ & $0,21 \mathrm{a}$ & 12,2 \\
\hline Número de nós no caule & $12,9 \mathrm{a}$ & $12,0 \mathrm{~b}$ & $11,9 \mathrm{~b}$ & 10,8 \\
\hline Número de ramos planta ${ }^{-1}$ & $2,75 \mathrm{a}$ & $2,25 \mathrm{~b}$ & $1,99 \mathrm{~b}$ & 20,3 \\
\hline Número de legumes no caule planta ${ }^{-1}$ & $35,5 \mathrm{a}$ & $28,9 \mathrm{~b}$ & $27,3 \mathrm{~b}$ & 15,5 \\
\hline Número de legumes nos ramos planta-12 & $17,2 \mathrm{a}$ & $10,3 \mathrm{~b}$ & $10,0 \mathrm{~b}$ & 19,8 \\
\hline Porcentagem dos legumes provenientes dos ramos & $30,8 \mathrm{a}$ & $25,8 \mathrm{a}$ & $26,2 \mathrm{a}$ & 30,8 \\
\hline Número de grãos legume ${ }^{-1}$ do caule & $2,25 \mathrm{a}$ & $2,12 \mathrm{a}$ & $2,07 \mathrm{a}$ & 15,12 \\
\hline Número de grãos legume ${ }^{-1}$ dos ramos & $2,39 \mathrm{a}$ & $2,34 \mathrm{a}$ & $2,11 \mathrm{a}$ & 32,2 \\
\hline Massa de mil grãos do caule (g) & $138 \mathrm{a}$ & $135 \mathrm{a}$ & $144 \mathrm{a}$ & 8,36 \\
\hline Massa de mil grãos dos ramos (g) & $136 \mathrm{a}$ & $136 \mathrm{a}$ & $144 \mathrm{a}$ & 18,5 \\
\hline Porcentagem da massa de grãos provenientes dos ramos & $31,0 \mathrm{a}$ & $25,6 \mathrm{~b}$ & $25,4 \mathrm{~b}$ & 20,2 \\
\hline Índice de colheita aparente & $0,44 \mathrm{a}$ & $0,43 \mathrm{a}$ & $0,44 \mathrm{a}$ & 5,2 \\
\hline Nota de acamamento & 2,1 & 2,0 & 2,2 & - \\
\hline
\end{tabular}

${ }^{1}$ Médias seguidas pelas mesmas letras não diferem entre si pelo teste de Tukey a $5 \%$ de probabilidade.

${ }^{2}$ Dados transformados em $\sqrt{(}(x+1)$

Fonte: Elaboração dos autores.

Foi constatado maior número de nós no caule, número de ramos planta $^{-1}$, número de legumes no caule e nos ramos planta $^{-1}$, porcentagem dos legumes provenientes dos ramos e porcentagem da massa de grãos provenientes dos ramos na menor densidade de plantas avaliada (Tabelas 3 e 4). Isso ocorreu porque, nessa situação, a disponibilidade de água, luz e nutrientes para cada indivíduo é maior, conferindo maior produção por planta e melhores condições para a ramificação (RAMBO et al., 2003; BOARD; KAHLON, 2013; LUCA; HUNGRIA, 2014).

Nos dois experimentos, a massa de mil grãos do caule e dos ramos e o índice de colheita aparente não variaram entre as densidades avaliadas (Tabelas 3 e 4). A massa de mil grãos de soja é pouco afetada pelo arranjo espacial das plantas (RAMBO et al., 2003). O índice de colheita aparente observado foi expressivamente inferior ao observado por Kuss et al. (2008), em função, principalmente, do déficit hídrico no final do enchimento dos grãos (Figura 1). Adicionalmente, não houve variações expressivas de acamamento das plantas entre as densidades testadas (Tabelas 3 e 4), embora, em geral, ocorra maior acamamento em maiores densidades de plantas (BOARD, 2001; BALBINOT JUNIOR, 2011).
No segundo experimento, em que o crescimento vegetativo foi maior, a nota de acamamento foi 2,1, enquanto no primeiro foi 1 (ausência). As demais variáveis medidas também não foram influenciadas pela densidade de plantas em ambas as épocas de semeadura (Tabelas 3 e 4).

O plantio cruzado não propiciou ganhos de rendimento de grãos nos dois experimentos (Tabelas 5 e 6), conferindo com resultados obtidos por Procópio et al. (2013). No primeiro experimento, os componentes de rendimento número de legumes no caule planta ${ }^{-1}$, número de legumes nos ramos planta ${ }^{-1}$ e número de grãos legume ${ }^{-1}$ do caule foram maiores no plantio não cruzado em relação ao cruzado. Por outro lado, os componentes de rendimento não foram afetados pelo plantio cruzado no segundo ensaio. É necessário mencionar que as cultivares, ambientes e interação entre esses dois fatores determinam os efeitos dos arranjos de plantas sobre o rendimento da soja (VENTIMIGLIA et al., 1999; PROCÓPIO et al., 2013). No primeiro experimento, a maior altura de plantas e ramificação ocorreu no plantio não cruzado em relação ao cruzado, o que não foi observado no segundo experimento. 
Tabela 5. Variáveis agronômicas da cultura da soja, cultivar BMX Potência RR, em duas disposições das fileiras (médias de três espaçamentos entre fileiras e três densidades de plantas). Primeira época de semeadura (04/11).

\begin{tabular}{|c|c|c|c|}
\hline \multirow[t]{2}{*}{ Variáveis agronômicas } & \multicolumn{2}{|c|}{ Disposição das fileiras } & \multirow[t]{2}{*}{$\mathrm{CV}(\%)$} \\
\hline & Cruzadas & Não cruzadas & \\
\hline Rendimento de grãos $\left(\mathrm{kg} \mathrm{ha}^{-1}\right)$ & $3.079 \mathrm{a}^{1}$ & $3.199 \mathrm{a}$ & 8,7 \\
\hline Altura de plantas (m) & $0,99 \mathrm{~b}$ & $1,04 \mathrm{a}$ & 5,7 \\
\hline Altura de inserção do primeiro legume (m) & $0,22 \mathrm{a}$ & $0,23 \mathrm{a}$ & 16,7 \\
\hline Número de nós no caule & $10,6 \mathrm{a}$ & $11,0 \mathrm{a}$ & 11,8 \\
\hline Número de ramos planta ${ }^{-1}$ & $1,61 \mathrm{~b}$ & $1,95 \mathrm{a}$ & 25,7 \\
\hline Número de legumes no caule planta ${ }^{-1}$ & $23,3 \mathrm{~b}$ & $26,0 \mathrm{a}$ & 19,3 \\
\hline Número de legumes nos ramos planta ${ }^{-12}$ & $8,8 \mathrm{~b}$ & $11,2 \mathrm{a}$ & 21,2 \\
\hline Porcentagem dos legumes provenientes dos ramos & $25,9 \mathrm{~b}$ & $28,8 \mathrm{a}$ & 20,6 \\
\hline Número de grãos legume ${ }^{-1}$ do caule & $2,08 \mathrm{~b}$ & $2,22 \mathrm{a}$ & 10,2 \\
\hline Número de grãos legume ${ }^{-1}$ dos ramos & $2,17 \mathrm{a}$ & $2,26 \mathrm{a}$ & 11,0 \\
\hline Massa de mil grãos do caule (g) & $125,4 \mathrm{a}$ & $126,8 \mathrm{a}$ & 13,0 \\
\hline Massa de mil grãos dos ramos (g) & $118,0 \mathrm{a}$ & 119,0 a & 15,0 \\
\hline Porcentagem da massa de grãos provenientes dos ramos & $25,4 \mathrm{a}$ & $27,9 \mathrm{a}$ & 21,4 \\
\hline Índice de colheita aparente & $0,40 \mathrm{a}$ & $0,42 \mathrm{a}$ & 9,7 \\
\hline Nota de acamamento & 1 & 1 & - \\
\hline
\end{tabular}

${ }^{1}$ Médias seguidas pelas mesmas letras não diferem entre si pelo teste de Tukey a 5\% de probabilidade.

${ }^{2}$ Dados transformados em $\sqrt{(}(x+1)$

Fonte: Elaboração dos autores.

Tabela 6. Variáveis agronômicas da cultura da soja, cultivar BMX Potência RR, em duas disposições das fileiras (médias de três espaçamentos entre fileiras e três densidades de plantas). Segunda época de semeadura (18/11).

\begin{tabular}{|c|c|c|c|}
\hline \multirow[t]{2}{*}{ Variáveis agronômicas } & \multicolumn{2}{|c|}{ Disposição das fileiras } & \multirow[t]{2}{*}{$\mathrm{CV}(\%)$} \\
\hline & Cruzadas & Não cruzadas & \\
\hline Rendimento de grãos $\left(\mathrm{kg} \mathrm{ha}^{-1}\right)$ & $3.132 \mathrm{a}^{1}$ & $3.037 \mathrm{a}$ & 6,5 \\
\hline Altura de plantas (m) & $1,14 \mathrm{a}$ & $1,15 \mathrm{a}$ & 3,8 \\
\hline Altura de inserção do primeiro legume (m) & $0,21 \mathrm{a}$ & $0,22 \mathrm{a}$ & 12,2 \\
\hline Número de nós no caule & $12,4 \mathrm{a}$ & $12,2 \mathrm{a}$ & 10,8 \\
\hline Número de ramos planta ${ }^{-1}$ & $2,4 \mathrm{a}$ & $2,3 \mathrm{a}$ & 20,3 \\
\hline Número de legumes no caule planta ${ }^{-1}$ & $30,8 \mathrm{a}$ & $30,4 \mathrm{a}$ & 15,5 \\
\hline Número de legumes nos ramos planta ${ }^{-12}$ & $12,8 \mathrm{a}$ & $12,2 \mathrm{a}$ & 19,8 \\
\hline Porcentagem dos legumes provenientes dos ramos & $27,3 \mathrm{a}$ & $27,8 \mathrm{a}$ & 30,8 \\
\hline Número de grãos legume $e^{-1}$ do caule & $2,13 \mathrm{a}$ & $2,16 \mathrm{a}$ & 15,1 \\
\hline Número de grãos legume ${ }^{-1}$ dos ramos & $2,33 \mathrm{a}$ & $2,29 \mathrm{a}$ & 32,2 \\
\hline Massa de mil grãos do caule (g) & $140 \mathrm{a}$ & $139 \mathrm{a}$ & 8,4 \\
\hline Massa de mil grãos dos ramos (g) & $137 \mathrm{a}$ & $140 \mathrm{a}$ & 18,5 \\
\hline Porcentagem da massa de grãos provenientes dos ramos & $28,1 \mathrm{a}$ & $26,6 \mathrm{a}$ & 20,2 \\
\hline Índice de colheita aparente & $0,44 \mathrm{a}$ & $0,44 \mathrm{a}$ & 5,2 \\
\hline Nota de acamamento & 1,9 & 2,4 & - \\
\hline
\end{tabular}

${ }^{1}$ Médias seguidas pelas mesmas letras não diferem entre si pelo teste de Tukey a $5 \%$ de probabilidade.

${ }^{2}$ Dados transformados em $\sqrt{ }(x+1)$

Fonte: Elaboração dos autores. 
Em relação ao plantio cruzado, é necessário salientar que com o cruzamento das linhas, a segunda semeadura, transversal à primeira, prejudica a qualidade da primeira operação, em virtude do revolvimento do solo ocasionado pela segunda passagem da semeadora e da compactação adicional imposta pelo rodado do trator e da semeadora (PROCÓPIO et al., 2013). O aumento do revolvimento do solo pode aumentar a erosão hídrica e a emergência de plantas daninhas. Além disso, é uma técnica que envolve o dobro do tempo e de horas máquina para realizar a semeadura, já que são necessárias duas operações de semeadura na mesma área.

\section{Conclusões}

$\mathrm{O}$ espaçamento de $0,45 \mathrm{~m}$ entre as fileiras proporcionou maior rendimento de grãos em relação aos espaçamentos de 0,30 e $0,60 \mathrm{~m}$.

A densidade de 300 mil plantas ha ${ }^{-1}$ proporcionou maior rendimento de grãos de soja em relação às densidades mais altas em semeaduras mais tardias.

O plantio cruzado não aumentou o desempenho produtivo na cultura da soja.

\section{Agradecimentos}

Ao $\mathrm{CNPq}$ pela concessão de bolsa de Produtividade em Desenvolvimento Tecnológico e Extensão Inovadora ao primeiro autor e bolsa de Produtividade em Pesquisa ao segundo autor.

\section{Referências}

BALBINOT JUNIOR, A. A. Acamamento de plantas na cultura da soja. Agropecuária Catarinense, Florianópolis, v. 25, n. 1, p. 40-43, 2011.

BOARD, J. Light interception efficiency and light quality affect yield compensation of soybean at low plant population. Crop Science, Madison, v. 40, n. 5, p. 1285-1294, 2001. Available at: <http://doi:10.2135/ cropsci2000.4051285x>. Accessed at: 18 ago. 2013.
BOARD, J. E.; KAHLON, C. Morphological responses to low plant population differ between soybean genotypes. Crop Science, Madison, v. 53, n. 3, p. 1109-1119, 2013. Available at: <https:/www.agronomy.org/publications/ cs/abstracts/53/3/1109>. Accessed at: 14 jun. 2014.

BOROOMANDAN, P.; KHORAMIVAFA, M.; HAGHI, Y.; EBRAHIMI, A. The effects of nitrogen starter fertilizer and plant density on yield, yield components and oil and protein content of soybean (Glycine max L. Merr). Pakistan Journal of Biological Sciences, Faisalabad, v. 12, n. 4, p. 378-382, 2009. Available at: $<$ http://www.ncbi.nlm.nih.gov/pubmed/19579973>. Accessed at: 14 jun. 2014.

BRUIN, J. L.; PEDERSEN, P. Effect of row spacing and seeding rate on soybean yield. Agronomy Journal, Madison, v. 100, n. 3, p. 704-710, 2008. Available at: $<$ http://doi:10.2134/agronj2007.0106>. Accessed at: 30 jul. 2013.

COOPERATIVE EXTENSION SERVICE AMES. How a soybean plant develops. Ames: Iowa State University of Science and Technology, 1994. 20 p.

COX, W. J.; CHERNEY, J. H. Growth and yield responses of soybean to row spacing and seeding rate. Agronomy Journal, Madison, v. 103, n. 1, p. 123-128, 2011. Available at: <http://doi:10.2134/agronj2010.0316>. Accessed at: 23 ago. 2013.

COX, W. J.; CHERNEY, J. H.; SHIELDS, E. Soybeans compensate at low seeding rate but not at high thinning rates. Agronomy Journal, Madison, v. 102, n. 4, p. 1238-1243, 2010. Available at: <http://doi:10.2134/ agronj2010.0047>. Accessed at: 23 ago. 2013.

FERREIRA, D. F. SISVAR: um programa para análises e ensino de estatística. Revista Symposium, Lavras, v. 6, n.2, p. 36-41, 2008.

HANNA, S.; CONLEY, S. P.; SHANER, G. E.; SANTINI, J. B. Fungicide application timing and row spacing effect on soybean canopy penetration and grain yield. Agronomy Journal, Madison, v. 100, n. 5, p. 1488-1492, 2008. Available at: <http://doi:10.2134/ agronj2007.0135>. Accessed at: 20 ago. 2013.

HEIFFIG, L. S.; CÂMARA, G. M. S.; MARQUES, L. A.; PEDROSO, D. B.; PIEDADE, S. M. S. Fechamento e índice de área foliar da cultura da soja em diferentes arranjos espaciais. Bragantia, Campinas, v. 65, n. 2, p. 285-295, 2006. Disponível em: <http://dx.doi. org/10.1590/S0006-87052006000200010>. Acesso em: 23 ago. 2013.

KUSS, R. C. R.; KÖNIG, O; DUTRA, L. M. C.; BELLÉ, R. A.; ROGGiA, S.; STURMER, G. R. População de plantas e estratégia de manejo de irrigação na cultura da 
soja. Ciência Rural, Santa Maria, v. 38, n. 4, p. 11331137, 2008. Disponível em: <http://dx.doi.org/10.1590/ S0103-84782008000400036>. Acesso em: 23 ago. 2013.

LIMA, S. F.; ALVAREZ, R. C. F.; THEODORO, G. F.; BAVARESCO, M.; SILVA, K. S. Efeito da semeadura em linhas cruzadas sobre a produtividade de grãos e severidade da ferrugem asiática da soja. Bioscience Journal, Uberlândia, v. 28, n. 6, p. 954-962, 2012. Disponível em: <http://www.seer.ufu.br/index.php/ biosciencejournal/article/view/13960/11106>. Acesso em: 23 ago. 2013.

LUCA, M. J.; HUNGRIA, M. Plant densities and modulation of symbiotic nitrogen fixation in soybean. Scientia Agricola, Piracicaba, v. 71, n. 3, p. 181187, 2014. Available at: <http://www.scielo.br/scielo. php?pid=S0103-90162014000300002\&script $=$ sci_ arttext>. Accessed at: 17 jun. 2014.

PIRES, J. L.; COSTA, J. A.; THOMAS, A. L. Rendimento de grãos de soja influenciado pelo arranjo de plantas e níveis de adubação. Pesquisa Agropecuária Gaúcha, Porto Alegre, v. 4, n. 2, p. 183-188, 1998.

PROCÓPIO, S. O.; BALBINOT JUNIOR, A. A.; DEBIASI, H.; FRANCHINI, J. C.; PANISON, F. Plantio cruzado na cultura da soja utilizando uma cultivar de hábito de crescimento indeterminado. Revista de Ciências Agrárias/Amazonian Journal of Agriculturaland Environmental Sciences, Belém, v. 56, n. 4, p. 319-325, 2013.
R DEVELOPMENT CORE TEAM. R: a language and environment for statistical computing. Vienna: $\mathrm{R}$ Foundation for Statistical Computing, 2009. 409 p.

Estimativa do potencial de rendimento por estrato do dossel da soja, em diferentes arranjos de plantas. Ciência Rural, Santa Maria, v. 34, n. 1, p. 33-40, 2004. Disponível em: $<$ http://dx.doi.org/10.1590/S010384782004000100006>. Acesso em: 23 ago. 2013.

RAMBO, L.; COSTA, J. A.; PIRES, J. L. F.; PARCIANELLO, G.; FERREIRA, F. G. Rendimento de grãos da soja em função do arranjo de plantas. Ciência Rural, Santa Maria, v. 33, n. 3, p. 405-411, 2003. Disponível em: $<$ http://dx.doi.org/10.1590/S010384782003000300003 >. Acesso em: 23 ago. 2013.

SILVA, W. B.; PETTER, F. A.; LIMA, L. B.; ANDRADE, F. R. Desenvolvimento inicial de Urochloa ruziziensis e desempenho agronômico da soja em diferentes arranjos espaciais no cerrado Mato-Grossense. Bragantia, Campinas, v. 72, n. 2, p. 146-153, 2013.

VENTIMIGLIA, L. A.; COSTA, J. A.; THOMAZ, A. L.; PIRES, J. L. F. Potencial de rendimento da soja em razão da disponibilidade de fósforo no solo e dos espaçamentos. Pesquisa Agropecuária Brasileira, Brasília, v. 34, n. 2, p. 195-199, 1999.

WALKER, E. R.; MENGISTU, A.; BELLALOUI, N.; KOGER, C. H.; ROBERTS, R. K.; LARSON, J. A. Plant population and row-spacing effects on maturity group III soybean. Agronomy Journal, Madison, v. 102, n. 3, p. 821-826, 2010. Available at: <http://doi:10.2134/ agronj2009.0219>. Accessed at: 7 ago. 2013. 